\title{
A little of Nepal: Nepali diaspora in the US in an age of globalization
}

- Lopita Nath

With the recent debates over immigration in the United States, the diaspora communities began to be constantly reminded of their own origins and had to make continuing efforts to feel at home in a foreign country and be accepted as members of the community, vis- $a$-vis their foreign origins. The Nepali diaspora is no different. Unlike other South Asians who had immigrated to the United States since the 1950's, the Nepali diaspora started migrating into this country in large numbers only in the last two decades. A new immigrant group, their experiences of adjustment, assimilation and incorporation in the USA were almost synonymous with changes brought about by globalization. They are transnational communities who inhabit both spaces going through a tremendous process of readjustment.

This article, while examining the Nepalis' efforts to negotiate between two worlds (hostland and homeland) through the striking realities of belonging to both, also examines issues of identity, assimilation, adjustment and notions of home expressed in their struggles to create a new sense of themselves in the process of self-construction which immigrants commonly encounter in the USA. The study is exploratory in nature and is expected to fill an important gap in scholarship of the South Asian as well as the Nepali diaspora in the United States.

The meaning of the diaspora has changed with time. Used originally to describe the "scattering" of the Jews from Palestine to different parts of the globe, it has now come to define the migration of groups, forced or voluntary, who have taken up residence in places other than their homeland. (Selvadurai, 2004, p.5). Notions of diaspora are now very diverse and have moved beyond earlier notions of "settler colonization," "catastrophic dispersal of people" or even, "trade and labor diaspora" (Cohen, 1997, p.135). The term is,

Bodhi, 3 (1), 106-119. ISSN 2091-0479. (C) 2009 Kathmandu University 
however, debated and widely contested. Steven Vertovec (1999) broadly explains, "Diaspora is the term often used today to describe practically any population which is considered 'deterritorialised' or 'transnational' -that which has originated in a land other than which it currently resides, and whose social, economic and political networks cross the borders of nationstates or, indeed, span the globe" (p. 5). Vertovec further mentions that such populations are growing, in prevalence, number and self awareness and also emerging as significant players in the construction of national narratives, regional alliances or global political economies.

The term "diaspora" is broader in its connotation, than the "immigrant" that is often used to describe foreign entrants. The latter is mainly concerned with the act of arrival, while the former broadly suggests a "process of becoming and changing and the dynamic cultural mixing" (Vertovec, 1999, p.5). The term immigrant is very narrow in its meaning and expression as being just concerned with the act of arriving; it also manages to give the sense of that person being a perpetual outsider, a newcomer at all times. Moreover, the idea of the diaspora while acknowledging the fact of immigration also recognizes the transition from an immigrant to a settler in the new homeland. It allows for a sense of identity based on a cultural mix, of one that the immigrant brought from his homeland and the one that he adopts in the new land. "The emphasis must shift to a sense of cultural identity that is eclectic and diverse, a sense of cultural identity that is transforming itself, making it new over and over again, a continuous work in progress" (ibid). The identity in question centers on various markers that, though similar, also has points of differences. It enables the diaspora to continue to evolve and grow and always be in the "process of becoming." It also acknowledges the collective identity of a common history, something that is always present in the background from which the diaspora draws when they need that reassurance of a common past in their new homeland.

Bodhi, 3 (1), 106-119. ISSN 2091-0479. (C) 2009 Kathmandu University 
Rethinking the contested notion of diaspora has become a necessity during this period of globalization. The diaspora is no longer confined to the narrow spaces, but is signified by a much more relaxed attitude, that might be characterized as "coming out." As Cohen (1997) remarks, "globalization has enhanced the practical, economic, and effective roles of diaspora showing them to be particularly adaptive forms of social organization" (p.135). Cohen also writes that diasporas have gradually evolved and have "refurbished" themselves on their way to the most recent phase, with mutations and new and changing forms along the way. The South Asian diaspora has thus evolved from the earlier notions of catastrophic dispersal, labor and trade diaspora to that of a sojourner in the globalized world. The Nepali diaspora has largely joined these old and new categories, while successfully holding their own.

\section{The Nepali diaspora}

A country of emigrants since the early times, the Nepalis had, however, only immigrated to countries in the Asiatic region. Their traditional destinations were India, Hong Kong, Japan and other areas in the Asiatic mainland ${ }^{1}$. This pattern of migration began to change since the 1970's, and the Nepalis began to opt for the gulf countries like Kuwait and Qatar. This triggered off a movement further west, rather than the east and more so, since the immigration laws in Hong Kong and Japan began to get vicious. The migration to the United States of America is fairly new, compared to their history of migration. The earlier migrants to the United States who managed to make it successfully (as noted from my interviews with migrants residing here for about thirty years now) belonged to a group

\footnotetext{
${ }^{1}$ The Nepali immigration to countries like India and Hong Kong and elsewhere in South and Southeast Asia dates back to the colonial period when the British began to recruit the Nepalis for the British army (Gurkha battalions) and also as laborers to work on the tea gardens and coal mines and later for any sundry job on a modest payment. This began a tradition of migration.
}

Bodhi, 3 (1), 106-119. ISSN 2091-0479. (C) 2009 Kathmandu University 
that dared to dream big. But this has changed since then. Data available on the number of Nepalis living in the United States is only an approximate, as they are scattered all over the country. According to the Institute of International Education (IIE), Open Doors $(2007)^{2}$, Report on the International Education Exchange, Nepal ranked 13 (7,754 students) in the list of the top leading countries of origin of foreign students in the US. This report also noted an increase of $27.9 \%$ over the previous year. This has increased over the years, which in the general estimate is only destined to grow as more people become aware of the possibilities and the US destination gets increasingly popular (IIE, 2007).

Nepalis have moved to America due to certain motivations. The first would be the desire to study in an advanced educational environment that US universities offer to foreign students. Also, people with this desire are facilitated by agencies which provide guidance and counseling back at home. Another motivation is the prospects for work and money. Some people even plunge into the loans offered by private banks for education abroad. The other factor that has aided in an increasing migration is the DV lottery system. The Diversity Visa (DV), formally, is a program "congressionally-mandated and allows up to 55,000 persons from nations that are historically under-represented in terms of migration to the United States to qualify each year for immigrant visas"( 2008) ${ }^{3}$. Since Nepal is on the eligibility list, a large number of Nepalis immigrate to the US on the DV lottery. These immigrants secure their Green Card and become permanent residents, and join the ranks of the diaspora without too much of a stress, unlike others who have to go through the Visa regulation process.

${ }^{2}$ Available online at

$<$ http://www.opendoors.iienetwork.org/file_depot/0-10000000/010000/3390/folder/58653/Fast+Facts+2007+Final.pdf $>$.

${ }^{3} \mathrm{http} / / / \mathrm{www}$. dvlottery.com

Bodhi, 3 (1), 106-119. ISSN 2091-0479. (C) 2009 Kathmandu University 


\section{Assimilation and adjustments}

Steven Vertovec's broad description of the diaspora in a "process of becoming and changing and the dynamic cultural mixing" (1999, p.5) fits in with the image of the diaspora in their new homeland. Further, the United States has often been described as a society that is always in the process of evolution, "permanently unfinished." This has again been a widely contested notion as scholars have refuted the older models of assimilation and incorporation for the recent immigrants. Recent immigrations are occurring in "a global context where nation states are no longer able to control the economic and cultural facets of its national life" (Appadurai, 1996). The diaspora are thus evolving under conditions of globalization and the processes of assimilation and incorporation are indeed based on these experiences. Although the Nepali diaspora are assimilating into the American way of life, they still hold on to their own cultural norms.

Nisha and Suchitra B. Shreshtha ${ }^{4}$ live in San Antonio, USA. Nisha is a registered nurse in San Antonio, while Suchitra has an M.S. in Engineering from Texas A\&M University and now holds a position at the South Texas Engineering. They live in a beautiful house with their two daughters, Niva (10) and Mizla (5). They are completely assimilated into the American way of life. Mizla is very fond of fast food and, on the day I met them, was to go out for a Subway dinner with her father. Although the girls speak Nepali and Newari (Suchitra is from the Kathmandu Valley of Nepal and speaks Newari), they speak English with an American accent and are much Americanized. However, Nisha and Suchitra seem to have had it a little easier than others. The process of adjustment to the new life is not as easy for other Nepalis, who also came with dreams of establishing themselves in America. With the first step on this land begins

\footnotetext{
${ }^{4}$ Interview with Nisha Shreshtha and Suchitra B. Shreshtha, in July 2008, San Antonio, Texas.
}

Bodhi, 3 (1), 106-119. ISSN 2091-0479. (C) 2009 Kathmandu University 
struggle, just to make sure that they don't altogether lose sight of their dreams.

Ram $^{5}$ came to the US from a small village of Kavre, a district near the capital city of Kathmandu in Nepal. Eldest of three brothers, and son of very simple parents, he had to work hard to keep the family land from being taken away by members of his extended family. He talks of his determination to do something in life in the face of all odds. "It was a difficult life" he said, repeatedly during the conversation. "We had land, but no running economy." He learnt the value of education early in life and realized its importance to give him a better life. He got a Bachelors of Science degree in Bio-medical Science in Nepal. He soon got a job in the Southwest Foundation for Biomedical Research (SWBR). He had hopes of making it big and even doing his Ph.D. in due course. He was good in his job and throughout his career in Nepal he had received offers to go to Canada and Japan for further studies and jobs, but he always refused as he wanted to come to the USA. He came on a job transfer to the SWBR, on a J-1 Visa and wanted to go on for higher studies. He went to the University of Texas, Health Science Center (UTHSC) but his B.Sc degree from Nepal was not accepted and he had to start all over again. He was too gullible and believed them and did not have the energy or the resources to fight for or plead his case. So he started all over, going over the core and other course requirements at UT, Galvenston, taking a few courses at a time. All this he had done while still working at the SWBR. He said "I work till 5pm at my job and lab" and then I go to the UT library and study till $9 \mathrm{pm}$ or $10 \mathrm{pm}$. Then go home to get ready for the next day. He finally graduated and is now taking a breathe before he goes on for higher studies.

Ram's experience was not a very downhill road. After the first year of his stay in the US, he went back and brought his two

\footnotetext{
${ }^{5}$ Ram Upadhyay, Interviewed in July 2008, San Antonio, Texas.
}

Bodhi, 3 (1), 106-119. ISSN 2091-0479. C 2009 Kathmandu University 
daughters and then the next year his wife and son. It is very interesting how his wife came after his daughters. The older daughter is preparing for a career in Neuro-surgery. The younger daughter is doing a nursing course at University of Texas at San Antonio (UTSA), while the son is an undergraduate at the Northwest Vista College. This is their $10^{\text {th }}$ year in the US. Ram mentioned that the children had been to an English medium school before coming to the US and did not have much problem adjusting.

His wife, however, was uneducated and had never been out of Nepal before. She did not speak English at all. After a few years in the US, she began to feel homesick and wanted to return to Nepal. With husband and children in school and work the whole day, she was very lonely. Ram tried to help her adjust and looked at various community education options at teaching language, computers, and social adjustment for immigrants. A very interesting story was how he and the children taught her to cross the road. He said, "I took her to the Medical Center crossing and taught her how to press the walk button and then wait and start walking as soon as the light goes on. Later, I waited in the parking lot and told the children to walk with her at least ten times so that she could learn to be fast and careful." All this made a difference and soon she was able to converse and go around on her own. She even got a job at McDonald's. She still has difficulty communicating but has become smarter and abler to manage both work and family. The son sometimes goes and helps her at McDonald's, just to make sure his mother is coping well.

A similar story was told by Mr. Shyam. He came to do his MBA, but his wife knew no English and was on a spouse visa, where she could not work. With the help of a Chinese friend's wife, she found a job at a restaurant owned by a Chinese friend of theirs. "She cooks great Chinese food" Shyam told me. Today his wife is an Assistant Nurse at a local hospital in San Antonio. Shyam is a professor at a community college and has even won awards for his great teaching.

Bodhi, 3 (1), 106-119. ISSN 2091-0479. (C) 2009 Kathmandu University 
These narratives are testimony to the hardships that the Nepali diaspora encounter. Not everyone succeeds in life and while there are accounts of those who have made it big, there are also stories of those who saw their dreams disappear like a mirage before their eyes. But the process of assimilation and adjustment continues and the diaspora struggle in their daily battle to establish their own identity.

\section{Notions of home and identity}

Vertovec (1999) has described the diaspora effort to settle in the new land as a continuous process, but also one where they begin to define their identity (p.6). In this direction, Nepalis not only began to evolve new cultural traits which were a mix of both worlds, but also began a process of reinventing their identity around cultural markers, which in most cases were traditionally Nepali like festivals, customs, rituals and language. The common history becomes a bond they share and draw from, for reassurance in their new homeland.

The Nepali diaspora wrestles with this identity based on a cultural mix. The first struggle is one of adaptation and adjustment in the new homeland. They go through a process of Americanization, which comes from adapting, and mimicking the American way of life. But for the Nepali diaspora, they often return back to their own ethnic groups which become support groups in the United States. Like other diaspora, the inability to let go of their own culture and to completely assimilate with mainstream American life, have forced the Nepalis to form Associations and social groups that allow them to keep in touch with other Nepalis.

The sense of being a Nepali is very strong among the Nepali diaspora in the US. The Nepali Association of Oregon website, proudly states that, "You can take a Nepali out of Nepal, but you cannot take Nepal out of a Nepali""

${ }^{6} \mathrm{http}: / /$ www.geocities.com/nepaloregon/

Bodhi, 3 (1), 106-119. ISSN 2091-0479. (C) 2009 Kathmandu University 
not being Nepali myself, I was able to see this in my association with the Nepalis in the United States. My first surprise was when I was invited by Nisha and Suchitra to their home. I was very impressed by the way they had managed to strike a balance between their life in the US and their Nepali origins. Their home was beautifully decorated with artifacts from Nepal which gave one the sense of belonging that they still had with their homeland. They revealed, "We mostly speak Nepali at home. We speak Nepali with Niva (the older daughter), but Newari with Mizla (the younger daughter), as we don't want her to grow up not knowing her native language. And Niva can understand both dialects. So, even in their day to day life they speak at least three languages at home. Language is so important to preserve our identity."

Similar thought was echoed by Mr. $\mathrm{Joshi}^{7}$ when he told me about his experiences of teaching Nepali to Nepalis in the US:

Let us imagine a scenario: a Nepali in the U.S. calls his Mom in Nepal. Before the actual conversation has begun his Mom wants to talk to his son. The person asks his son who is playing Nintendo to talk to his Grandma. The boy reluctantly picks up the phone. But within 10 seconds he is back playing Nintendo complaining that he can't understand Grandma. At this point, the person may respond in one of the following ways: 1) becoming upset with the boy for being rude to his Grandma, 2) feel sorry for his Mom not learning to speak English, or 3) blame himself for creating this undesirable situation. Five years ago, we were in this exact situation and realized that we had been making a big mistake. So we began to teach Nepali to our children immediately. Surprisingly, at the outset, we had to face opposition from a relative. While the relative was visiting us we requested him to talk to our child, Ashish, in Nepali. He argued that since the

\footnotetext{
${ }^{7}$ Interview with Mr. Puspa Joshi. August 2008, San Antonio, Texas.
} 
child was born in the U.S. he is an American. As the child is learning English we should not bother ourselves by teaching him Nepali. Despite his opposition, we not only continued to teach our children, but also started our language class in Columbus in March 1995.

The above words are quoted from Joshi's paper documenting his efforts at teaching the Nepali language to Nepali children in the US (1997). He mentions that he could not continue with his dream project, but he did have some success. Parents of the children whom he taught told him how their sons and daughters were beginning to speak Nepali at home, even though they were not very fluent. But these small endeavors did go a long way in reaffirming their Nepaliness. This also allowed them to keep their notions of home alive, at least for themselves and their children, some of whom had never been to Nepal or go ever so infrequently. Celebrations of festivals like Dashain and Tika, together kept the feelings strong. The Nepali Associations do a good job of bringing together Nepalis during the times of festivals so as to keep alive and nurture the traditions that most of them grew up with. From my experiences with Nepali communities and individuals I interacted with, I learnt that they used cultural markers like dress, and festivals to assert their Nepaliness. This was very explicit among the women, especially the older women, who were very traditionally dressed for these occasions. Even though they appear very americanized when outside, within the group, and on festivals and occasions they kept their cultural markers intact.

In the younger generation of immigrants - students or young graduates holding their first jobs -American-ness is apparent. They do not feel constrained by identity markers like dress, etc. though they do speak the language and attend these festivals. And one can expect this to become even less important to their children. The young children are already showing signs of becoming Americanized. Hence, the efforts by the likes of 
Puspa Joshi to start Nepali language classes in the US are a big step in this direction.

Shyam said that his children, Deepak (19) and Deepa (10) are very much Americanized. At home they are Nepali, but once out of the threshold, they are Americans. He mentions how his son refused to go to school when he was just four years old as he did not understand English. "But," he said, "I feel so good when I think back to those days. Within a few months, my son was speaking fluent English and loved to go to school." Now he is a sophomore at UTSA and hopes to be a doctor. Shyam said that his son is focused and committed. Deepa is also very American outside the house. She is on the swim team at her school and is very independent.

Shyam is very proud of his children and has great hopes. He wants his children to have a better life than he had and achieve more with lesser struggles in life. The same thoughts were echoed by Ram. He said that the children did not understand the struggles of the parents. They can never imagine the life that their parents had. Sometimes, they cannot understand why their father is still studying.

Mr. Joshi also shared similar thoughts with me, "I am still full Nepali, but my two children are American Citizens. They behave that way. However, they do sometimes show part of Nepali culture. One is living in Nepal, trying to adjust there."

The one fear that many have expressed is the notion of their homeland. They still retain the image of the Nepal that they left behind. Those who had not been able to go back as often do indicate a serious disconnection with the idea of what home/Nepal is. When asked if he wanted to return, Shyam remarked, "When I am ready to go back, who will know me? The charm will not exist. Everything will be different." This thought continues to haunt many who wish to return at some point thinking that globalization and easier communication may make it a possibility.

Bodhi, 3 (1), 106-119. ISSN 2091-0479. (C) 2009 Kathmandu University 


\section{Globalization, diaspora and a new sense of self}

The South Asian diasporas, of USA in particular, move back and forth constantly renewing their migrant experience. They develop new identities and are "constantly producing and reproducing themselves anew, through transformation and difference." Such processes are never smooth, especially with the global media and communication. As Appadurai (1996), has remarked, "Complex transnational flows of media images and messages perhaps create the greatest disjuncture for diasporic populations, since the electronic media in particular, the politics of desire and imagination are always in contest with the politics of heritage and nostalgia." They constantly find their own established ideas of what their homeland was when they left and how it has grown during their time away, being challenged by the new image that they see when they visit, or through the media. They thus have to integrate this new image into their minds and work towards accepting the changes. But the greatest challenge they face is perhaps trying to find a niche in the old homeland that they left behind.

Suchitra has founded the "Nepal American International Education Foundation" in the memory of his late mother, to help students in Nepal. He funds it mostly himself with some other donors among the Nepali community. They offer scholarship to meritorious High School students in Nepal. There are other such organizations funded by the Non-resident Nepalis (NRN) as they are called. However, some are hesitant to become too involved, mainly as they themselves, like Ram, are struggling to be established. Or others, like Shyam, who feel that unless there is someone in Nepal to manage the funds and see that it gets to the right person, such endeavors are wasted. He says, that "But I help Nepalis when they come to the US. They can call me for all kinds of advice." $\mathrm{He}$ is an accountant and so he also helps them with their taxes and gives tax advice to people.

Bodhi, 3 (1), 106-119. ISSN 2091-0479. (C) 2009 Kathmandu University 
What do these instances signify? In most cases the Nepali diaspora have successfully negotiated the reality of belonging to two worlds. Unlike other diaspora communities whose migrations were linked to some crises at home, the Nepali diaspora migrates voluntarily. They either come for education or for employment. They are considered among the privileged in their country for making it to the United States. The fact that in most cases they have a successful life to show for generates a sense of pride, when meeting their friends and family at home. Although in many cases one notices some compartmentalization of their two lives, media, cheaper communication and easier connections have helped. Although, they do not visit home very often, they all agree that it has become easier to keep in touch. Again, often the Nepali diaspora have family and friends visiting them in their homes in the US, and when they return they carry with them a sense of what the world of the diaspora in their foreign homeland is. They often serve as a bridge between the two worlds of the diaspora.

The Nepali diaspora has been affected by globalization. They are very transnational and many have maintained connections in both countries. The Non-Resident Nepalis (NRN) have also emerged as a strong voice in political as well as policy decisions back home as they are also a major source of funds for any development projects. But the Nepali diaspora is still grappling with the issues of settlement, assimilation and adjustment in their new homeland. As a fairly new group, and smaller in numbers, they do not have a long history or experience to fall back on and learn. They are trying to create both and also in the process define their image as members of the South Asian diaspora.

Bodhi, 3 (1), 106-119. ISSN 2091-0479. (C) 2009 Kathmandu University 


\section{References}

Appadurai, A. (1996). Modernity at Large: Cultural dimensions of globalization. Minneapolis, MN: University of Minnesota Press.

Cohen, R. (1997). Diasporas, the nation-state, and globalization. In W. G. Wu (Ed.), Global history and migrations (pp.117-143). Colorado: West View Press.

Joshi, P. M. and Joshi, A. L. (1997, May 25). The joys and sorrows of teaching Nepali to Nepali in the U.S. 16th Annual Convention of Association of Nepalese in Mid-West America, Chicago.

Selvadurai, S. (Ed.). (2004). Story-wallah. New York: Houghton Mifflin.

Vertovec, S. (1999). Three meanings of diaspora exemplified among South Asian religions. Diaspora, 7 (2), 1-37. Retrieved from http://www.transcomm.ox.ac.uk/ working\%20papers/diaspora.pdf.

Bodhi, 3 (1), 106-119. ISSN 2091-0479. (C) 2009 Kathmandu University 